\title{
Spatial Citizenship
}

\section{Dorothee Quade, Tilo Felgenhauer and Nicole Ferber (Eds.)}
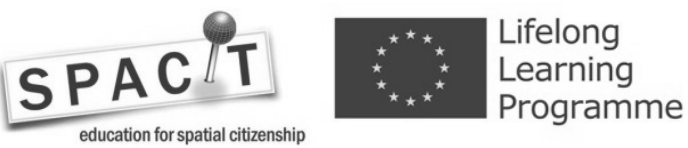

This publication is part of the EU-funded Comenius multilateral project

Spatial Citizenship 517908-LLP-1-2011-1-AT-COMENIUS-CMP.

It reflects the views only of the authors, and the Commission cannot be held responsible for any use which may be made of the information contained therein. 